\title{
Convection of a micropolar fluid with stretch
}

\author{
U. WALZER $\left(^{*}\right)$
}

Received on II:y 22nd, 1976

\begin{abstract}
Sumary. - As a model for the Benard convection in the asthenosphere the problem of the hydrodynamic stability of an infinite horizontal layer is calculated. The layer consists of a micropolar fluid with streteh. The field equations for the volocity vector, microrotation vector, microstretch, microinertia, density, temperature, and pressure form a system of eleven partial differential equations for the determination of eleven $n$ known sealar functions. We suceed in deconpling the system and reducing the problem to an ordinary differential equation. The analytical solution can be griven for the special case of a micropolar boussinesq fluid.
\end{abstract}

Zusamexlassuxg. - Als Modell für die Bénard-Konvektion in der Asthenosphäre wird das hychodynamische Stabilitatsproblem einer unendlichen horizontalen schicht berechnet. Die schicht besteht aus einer kom. pressiblen mikropolaren Flüssigkeit. Die Feldgleichungen für den Gesehwindigkeitsvektor, den Mikrorotationsgeschwindigkeitsvektor, die Mikrodeformation, das Mikroträgheitsmoment, die Dichte, die Temperatur und den Druek bilden ein Sistem von elf particllen Differentialgleichungen zur Bestimmung von elf unbekannten skalaren Funktionen. Es gelingt, das System zu entkoppeln und das Problem anf eine gewönliche Differentialgleichung zu reduzieren. Für den spezialfall einer mikropolaren BonssinesqFlüssigkeit kamn die analytische Lösung angegeben werden.

Rrassuxto. - - Il problema della stabilità idrodinamica di uno strato infinito orizzontale viene trattato cone un modello per la convenzione Benard nell astenosfera. Lo strato è formato da un fluido micropolare "with stretch". L insieme delle equazioni per il vettore velocita, il vettore mierorotazione, la mierodeformazione, la mieroinerzia, la densita, la temperatura e la pressione, forma un sistema di ll equazioni differenziali parziali che

(*) Zentralinstitut für Plyssik der Erde. Akad. Wiss. DDR, Institutsfoil Jena, 69 Jena (J)J)R), Burgweg 11: Z1PE Mitt. Nr. 542. 
serve a determinare le 11 funzioni scalari incognite. Si raggiunge lo scopo decuplicando il sistema e riducendo il problema ad un'equazione differenziale ordinaria. Si può dare la soluzione analitica solo nel easo di un fhuido micropolare Boussinesq.

\section{INTRODUCTION}

When investigating flow phenomena in the Earth's mantle, a Newtonian fluid is mostly used as constitutive equation. This assumption is fully justified as an approximation and has often been user successfully $(3,5,9,11,14)$. From shear tests of possible mantle

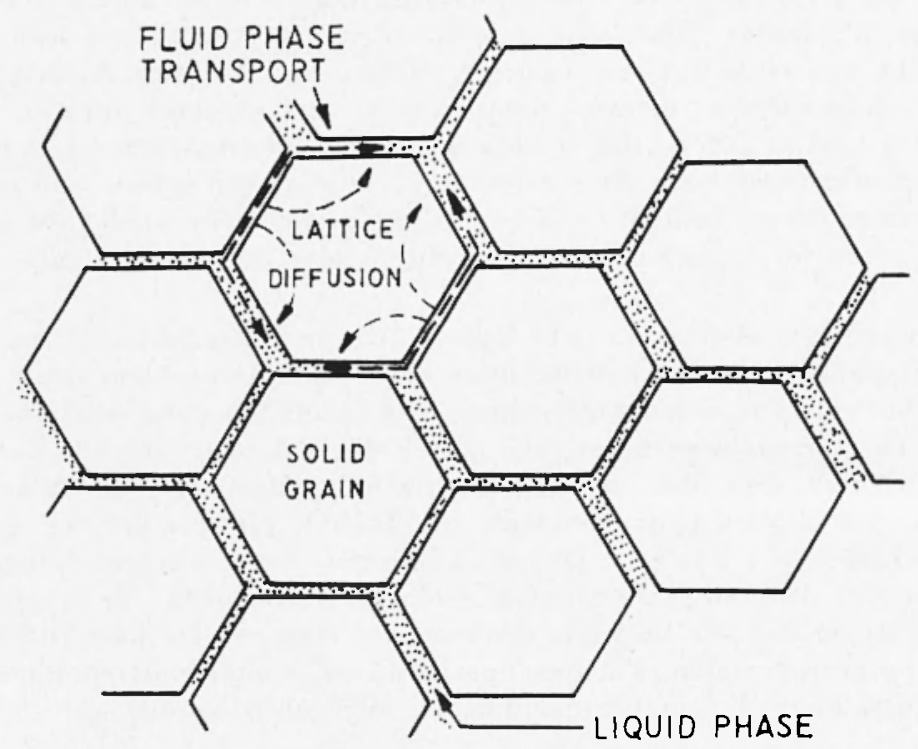

Fig. I - Schematic representation of the geometry of the two phases of low-velocity layer material. After Stocker and $A$ shlig $\left({ }^{12}\right)$.

rock $\left(^{8}\right)$, from the postglacial uplift of Fennoscandia $\left({ }^{10}\right)$, and from theoretical considerations $\left(^{18}\right)$ it is concluded that a power law fluid with the exponent 3 is a more realistic model for the solid portions of the mantle. For the corresponding convection based on solid creep 
a theory has been ileveloperl (17). In another approach (15), used to gain information on the convection current pattern in the Earth's mantle, the question as to the constitutive equation is evaderl. Some simple assumptions are marle regarding the kinematics of the stream lines which appear to be plausible from the point of view of fluir mechanies. These assumptions, together with the geometry of the mantle, learl to certain possible morles of flow which would create a topography on the surface of the Earth which is similar to the ob-

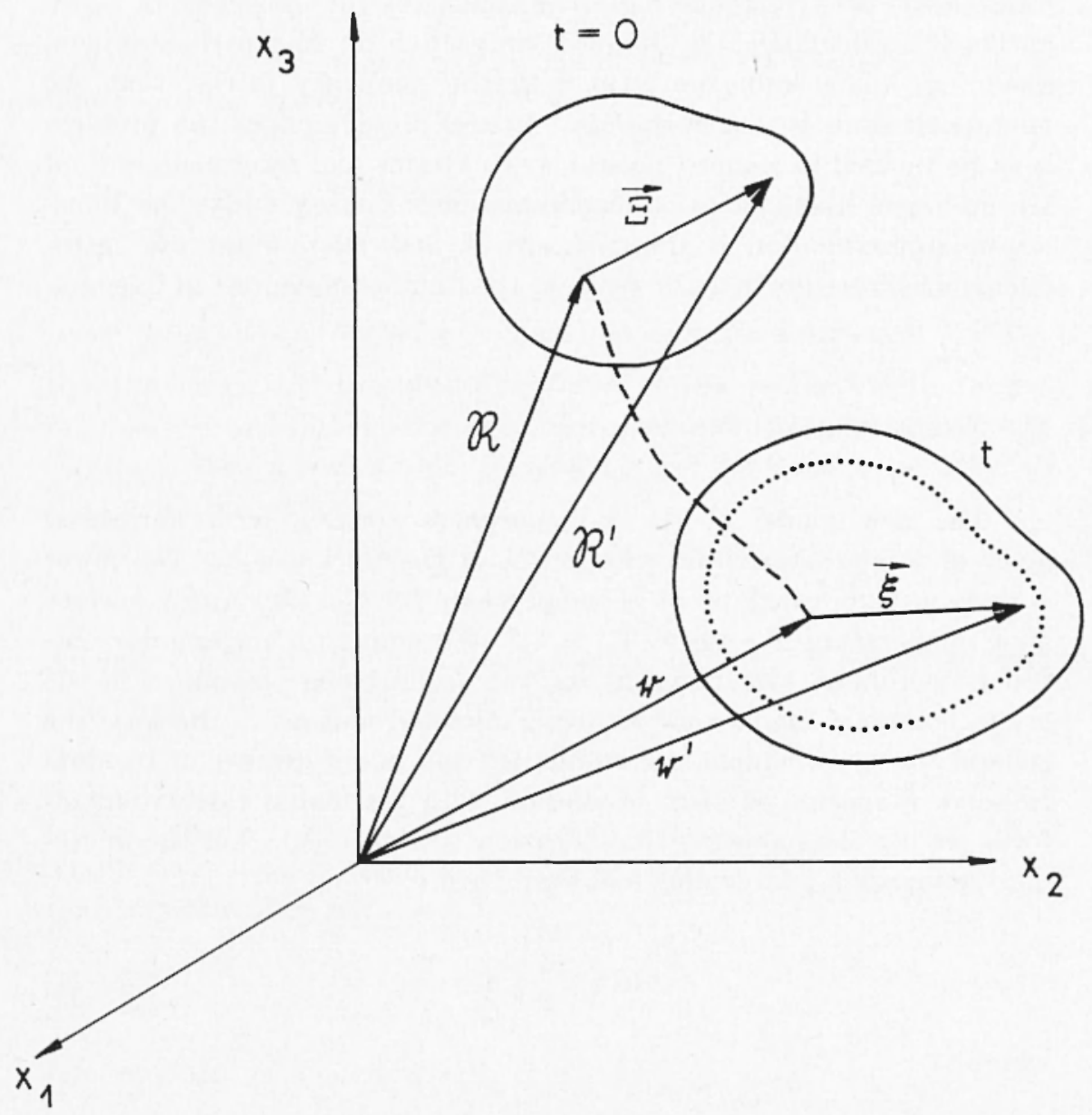

Figr. 2 - Translation, rotation and isotropic microstreteh of an clement of a micropolar fluid with stretcli. 
serverl one. Recently, the low-velocity layer of the npper mantle has been assumed to be partly molten ${ }^{1}$ ). If the geometrical connection between the two phases exists in the form (see Fig. 1) suggested by Stocker and Ashby (12), a micropolar fluid may be assumed as a constitutive equation. In such a merlium, in arlition to the three translatory degrees of freedom of conventional continuum mechanies, three rotational degrees of freedom are assigned to each spatial point with the help of which the rotation of the solid grains of Fig. 1 may be described. While some anthors have already tried to work with micropolar elastic merlia (e. E., Teisseyre $\left({ }^{13}\right)$, Bosehi (2)), Cosserat fluids have been introduced only recently (16) into greophysics. The author $\left({ }^{16}\right)$ calculated the Binard convection in the asthenosphere, assuming, apart from the term with the buoyancy forces, that the micropolar fluid is incompressible. In the present paper the problem is to be tackled in a more general way. Grains and intermediate fluid are no longer assumed to be incompressible. Consequently, the Boussinesq approximation is dropped, stretch and microstretch are introduced, which results in an increase of the number of degrees of freedom.

\section{1. - Governing; equations}

The new morlel of the asthenosphere consists of a horizontal layer of a micropolar fluid with stretch of the thickness h. The lower surface is kept constant at a temperature $T_{0}$ and the upper surface at a temperature $T_{1}$, where $T_{0}>T_{1}$. We employ a rectangular cartesian coordinate system $x_{1}, x_{2}, x_{3}$, the origin being positioned in the lower boundary plane and $\mathrm{x}_{3}$ being directed upwards. Because the general theory of simple microfluids has too many degrees of freedom to solve a special problem of motion with justifiable calculation efforts, we use the following simplifieations (Eringen ( $\left.{ }^{7}\right)$ ). Let the microinertia tensor $i_{k 1}$ have the following form:

$$
\mathrm{i}_{\mathrm{k} 1}=\frac{1}{2} \mathrm{j} \delta_{\mathrm{k} 1}
$$

where

$$
\delta_{k 1}= \begin{cases}1 & \text { for } k=1 \\ 0 & \text { for } k \neq 1\end{cases}
$$


and $\mathrm{j}$ is a scalar quantity, i. e., the fluid is microisotropic. Let the gyration tensor $n_{k 1}$ have + independent scalar functions instear of 9 :

$$
n_{k 1}=n \delta_{k 1}+e_{k 1 r} n_{r}
$$

where

$$
e_{\mathrm{k} 1 \mathrm{r}}=\left\{\begin{array}{cl}
1 & \text { for }(\mathrm{klr})^{\mathrm{cyc}}=\left(\begin{array}{lll}
1 & 2 & 3
\end{array}\right) \\
-1 & \text { for }(\mathrm{kll})^{\mathrm{cyc} 1}=\left(\begin{array}{lll}
1 & 3 & 2
\end{array}\right) \\
0 & \text { for other cases }
\end{array}\right.
$$

$\mathrm{n}$ or $\mathrm{n}_{\mathrm{r}}=$ microrotation vector and $\mathrm{n}=$ microstretch. The significance of these quantities is demonstrated in Fig. 2 . In the time $t$, point $R$ of the fluid moves to $r$, noint $R^{\cdot}$ to $r^{*}$. The vector $\vec{\zeta}(t)$ or $\breve{\zeta}_{k}(t)$ represents the micromotion:

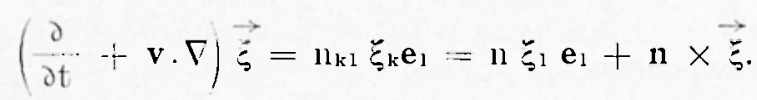

Vectors are indicated by bold-face letters or by arrows over the letters. $\quad \mathrm{v}$ or $\mathrm{v}_{\mathrm{r}}=$ velocity, $\mathrm{e}_{1}=$ unit vector in the l-direction. Equation [5] shows that the total derivative of the rector $\vec{\xi}$ with respect to time can be subdivided into an isotropic microstretch and a microrotation. The microrotation generally is not identical with the classical rotation vector.

$$
\text { (1) } \mathrm{r}=\frac{1}{2} \mathrm{e}_{\mathrm{rk1} 1} \mathrm{r}_{1, \mathrm{k}}
$$

An index followed by a comma means a partial differentiation with respect to space variable $x_{k}$, e. $g$.,

$$
v_{1, k}=\frac{\partial v_{1}}{\partial \mathbf{x}_{k}} \text {. }
$$

The basic laws of motion of micropolar stretch fluids are:

Conservation of mass:

$$
\frac{\partial p}{\partial t}+\nabla \cdot(p v)=0 .
$$

Conservation of microinertia:

$$
\left(\frac{\partial}{\partial t}+v \cdot \nabla\right) \mathrm{j} \ldots .2 n j=0 .
$$


Balance of first stress moments:

$$
\begin{gathered}
(\alpha+\beta) \nabla \nabla \cdot \mathbf{n}+\gamma \nabla \cdot \mathbf{n}+\varkappa \nabla \times \mathbf{v}-2 \varkappa \mathrm{n}+\rho \mathrm{d}=\mathrm{pj}\left(\frac{\partial}{\partial \mathrm{t}}+\mathbf{v} \cdot \nabla\right) \mathbf{n}, \\
\alpha_{0} \nabla^{2} n-\left(\eta_{0}-\lambda_{0}\right) \mathrm{n}+\rho \mathrm{dl}^{*}=\frac{1}{2} \rho \mathrm{j}\left(\frac{\partial}{\partial \mathrm{t}}+\mathrm{v} \cdot \nabla\right) \mathrm{n} .
\end{gathered}
$$

Conservation of energy:

$$
\begin{aligned}
& \rho c_{v}\left(\frac{\partial}{\partial t}+v_{k} \frac{\partial}{\partial x_{k}}\right) T=-p d_{k k}+\lambda_{o} n d_{k k}+\lambda d_{k k} d_{11}+
\end{aligned}
$$

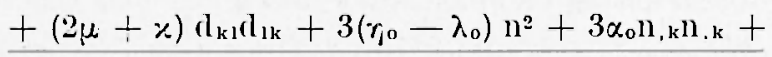

$$
\begin{aligned}
& \left.+\left(3 \alpha_{1}+\beta_{0}\right) e_{k 1 r} n_{1, k} n_{r}+2 \omega_{k}-\omega_{k}\right)\left(\omega_{k}-n_{k}\right)+ \\
& +\alpha n_{k, k} n_{1,1}+\beta n_{k, 1} n_{1, k}+\gamma n_{1, k} n_{1, k}+x^{*} T_{, k k}+Q
\end{aligned}
$$

Balance of momentum:

$$
\begin{aligned}
& -\nabla \mathrm{p}+\lambda_{0} \nabla \mathbf{n}+(\lambda+\mu) \nabla \nabla \cdot \mathbf{v}+(\mu+\varkappa) \nabla^{2} \mathbf{v}+\varkappa \nabla \times \mathbf{n}+ \\
& +\rho \mathbf{f}=\rho\left(\frac{\partial}{\partial \mathrm{t}}+\underline{\mathbf{v} \cdot \nabla}\right) \mathbf{v} .
\end{aligned}
$$

Equation of state:

$$
\rho=\rho_{0}\left[1-\delta\left(T-T_{0}\right)\right]
$$

the classical spin tensor being denoted by $\mathbf{d}_{\mathrm{k} 1}$.

$$
d_{k 1}=\frac{1}{2}\left(v_{k, 1}+v_{1, k}\right)
$$

$p=$ density $; \mathrm{T}=$ absolute temperature $\mathrm{p}=$ pressure; $\mathbf{f}=$ body force per unit mass; $d=$ axial vector of the first borly moments per unit mass which are closely connected with the microrotation $\mathbf{n} ; \mathbf{l}^{*}=$ first borly moment per unit mass which is closely romnected with the microstretch $n ; \mathrm{c}_{\mathrm{v}}=$ specific heat at constant volume; $\chi^{*}=$ coefficient of heat conduction; $Q=$ heat producerl within the fluirl per unit volume per unit time; $\alpha, \alpha_{0}, \alpha_{1}, \beta, \beta_{0}, \gamma, \chi, \eta_{0}, \lambda, \lambda_{0}, \mu=$ viscosity constants; $\delta=$ thermal expansion coefficient; $\rho_{0}=$ density at the fixed temperature $\mathrm{T}_{0}$.

The relationships [8] to [14] are eleven scalar equations for the determination of eleven scalar unknowns: $v_{k}, n_{k}, n, j, \rho, T, p$. Compared with the fundamental equations of a micropolar fluid without 
stretch $\left({ }^{1 i}\right)$, $n$ and $j$ are additional sought functions. f, d, and $d^{*}$ are to be given quantities. As Eringen ( $)$ and Erdogan ( $\left.{ }^{6}\right)$ have found, the material constants are subject to certain restrictions which are necessary and sufficient to ensure the validity of the principle of entropy:

$$
\left.\begin{array}{lll}
3 \lambda+2 \mu+x \geqslant 0 ; & 2 \mu+x \geqslant 0 ; & \varkappa \geqslant 0\} \text { where } \\
3 \alpha+\beta \gamma \quad \geqslant 0 ; & -\gamma \leqslant \beta \leqslant \gamma ; & \gamma \geqslant 0
\end{array}\right\} \mathrm{T} \neq 0
$$

and

$$
\alpha_{0} \geqslant 0 ; \quad r_{0}-\lambda_{0} \geqslant 0 ; \quad\left(\eta_{0}-\lambda_{0}\right)(3 \lambda+2 \mu+x) \geqslant \frac{\lambda_{0}^{2}}{4} .
$$

Let us now make some highly justified simplifications. The quantities $\mathbf{v}, \mathbf{n}$ and $n$ are so small in the asthenospliere that quadratic and mixed quadratic terms thereof may be neglected. Therefore, the underlined expressions of the formulas [10] to [13] are neglecterl. The accelerations $\mathrm{d}$ and $\mathrm{d}^{*}$ are to disappear. Let, furthermore $\mathrm{f}$ be equal to $\mathrm{g}$, i. e., only the gravity acceleration is assumed to be effective. Thus, the governing equations [8] to [1.4] are simplified to [18] to [24]

$$
\begin{aligned}
& \frac{\partial \rho}{\partial t}+\mathbf{v} \cdot \nabla \rho+\rho \nabla \cdot \mathbf{v}=\mathbf{0} \\
& \frac{\partial j}{\partial t}+\mathbf{v} \cdot \nabla j-2 n j=0 \\
& (\alpha+\beta) \nabla \nabla \cdot \mathbf{n}+\gamma^{2} \mathbf{n}+\varkappa \nabla \times \mathbf{v}-2 \varkappa \mathbf{n}=\rho \mathbf{j} \frac{\lambda \mathbf{n}}{\mathrm{it}}, \\
& \alpha_{0} \nabla^{2} \mathrm{n}-\left(r_{0}-\lambda_{0}\right) n=\frac{1}{2} \rho j \frac{\partial n}{\partial t}, \\
& \frac{\partial \mathrm{T}}{\mathrm{ot}}+\mathbf{v} \cdot \nabla \mathrm{T}=-\mathrm{c} \mathrm{p} \nabla \cdot \mathrm{v}+\mathrm{k} \nabla^{2} \mathrm{~T}+\mathrm{q} \\
& -\nabla_{\mathrm{l}}+\lambda_{\mathrm{o}} \nabla \mathrm{n}+(\lambda+\mu) \nabla \nabla \cdot \mathrm{v}+\left(\mu+x^{2} \mathbf{v}+\right. \\
& +x \nabla \times \mathbf{n}+\rho \mathbf{g}=\rho \frac{\partial \mathbf{v}}{\partial t} \\
& \rho=\rho_{0}\left[1-\delta\left(T-T_{0}\right)\right]
\end{aligned}
$$

where

$$
\mathrm{c}=\frac{1}{\rho \mathrm{c}_{\mathrm{v}}} ; \quad \mathrm{k}=\frac{\chi^{*}}{\rho \mathrm{c}_{\mathrm{v}}} ; \quad \mathrm{q}=\frac{\mathrm{Q}}{\rho \mathrm{c}_{\mathrm{v}}} \text {. }
$$




\section{2. - LINEARIZED GOVERNIXG EQUATIONS}

Jet us now assume that the principle of exchange of stabilities ( ${ }^{4}$ ) is valid, i. e., the current is considered to be stationary at the beginning. In the marginal state at the beginning of convection the mean state is assumed to be equal to the equilibrium state, and all variables should be representable as sums of equilibrium quantities which are functions of $\mathrm{x}_{3}$ only, and of small perturbations which are functions of $x_{1}, x_{2}, x_{3}$, and $t$ :

$$
\begin{array}{lll}
\mathrm{v}=\mathrm{p}+\mathrm{v}^{\prime} ; & \mathbf{T}=\overline{\mathbf{T}}+\mathrm{T}^{\prime} ; & \mathrm{p}=\mathrm{p}+\mathrm{\rho}^{\prime} \\
\mathbf{v}=\mathbf{v} ; & \mathbf{n}=\mathbf{n} ; & \mathbf{n}=\mathbf{n} .
\end{array}
$$

Mean state variables are denoted by an overbar.

Per definitionem there must not occur any motions in the equilibrium state:

$$
\mathbf{v}=0 ; \quad \mathrm{n}=0 ; \quad \mathrm{n}=0
$$

Hence, it follows from $[\ddot{2} 2]$ :

$$
\begin{aligned}
& \nabla^{2} \bar{T}=-\frac{\mathrm{q}}{\mathrm{k}} ; \quad \frac{\mathrm{d}^{2}}{\overline{\mathrm{u}_{3}^{2}}} \overline{\mathbf{T}}=-\frac{{ }^{-1}}{\mathrm{k}}, \\
& \bar{T}=\frac{-\mathrm{I}}{2 \mathrm{H}}\left(\mathrm{hx}_{3}-\mathrm{x}_{3}^{2}\right)-\frac{\mathrm{T}_{\mathrm{o}}-\mathrm{T}_{1}}{\mathrm{~h}} \mathrm{x}_{3}+\mathrm{T}_{\mathrm{o}}
\end{aligned}
$$

From [23] and [27]

$$
\nabla \overline{\mathrm{p}}=\bar{\rho} \mathrm{g} ; \quad \frac{\mathrm{d} \bar{p}}{\overline{\mathrm{d} \mathrm{x}_{3}}}=-\bar{\rho} \mathrm{g} ; \quad \overline{\mathrm{j}}=\bar{\rho} \mathrm{g}\left(\mathrm{h}-\mathrm{x}_{3}\right)+\mathrm{p}_{1}
$$

$\mathbf{g}=-\mathrm{g}_{\mathrm{i}}$ being used, and the constant pressure at the upper boundary surface of the layer being denoted by p. From [24] and [27] we obtain

$$
\bar{\rho}=\rho_{0}\left[1-\delta\left(\bar{T}-T_{0}\right)\right]
$$

Trivially, the other governing equations are satisfier by [27]. Eq. [27], [ะ9], [30], and [31] are the solutions for the static case.

In order to obtain the linearized fundamental equations, we now substitute [26] into the equations [18] to [27], the mean state vari- 
ables being known now from the statics. We renounce here the introduction of the Boussinesq approximation usual at this point, since it is exactly here where the theory is to be extended by stretch and microstretch. We obtain:

$$
\begin{aligned}
& \frac{\partial \rho^{\prime}}{\partial \mathrm{t}}+\mathbf{v} \cdot \nabla \bar{\rho}+\bar{\rho} \nabla \cdot \mathbf{v}=\mathbf{0} \\
& \frac{\partial j}{\partial t}+\mathbf{v} \cdot \nabla j-2 n j=0, \\
& (\alpha+\beta) \nabla \nabla \cdot n+\gamma \nabla^{2} n+x \nabla \times v-2{ }^{2} n=\rho j \frac{\lambda n}{\partial t}, \\
& \nabla^{2} n=v^{2} n+\frac{1}{2 \alpha_{0}} \bar{\rho} \mathrm{j}-\frac{\partial n}{\partial t}, \\
& \frac{\partial \mathrm{T}^{\prime}}{\text { ot }}+\mathbf{v} \cdot \nabla \overline{\mathrm{T}}=-\mathrm{c} \overline{\mathrm{p}} \nabla \cdot \mathrm{v}+\mathrm{k} \nabla^{2} \mathrm{~T}^{\prime}, \\
& -\nabla p^{\prime}+\lambda_{0} \nabla n+\rho^{\prime} \mathbf{g}+(\lambda+\mu) \nabla \nabla \cdot \mathbf{v}+\left(\mu+\nu^{2}\right) \nabla^{2} \mathbf{v}+ \\
& +x \nabla \times \mathbf{n}=\bar{p} \frac{\partial v}{\partial t} \text {, } \\
& \rho^{\prime}=-\rho_{0} \delta T^{\prime}
\end{aligned}
$$

$v^{2}$ is defined by

$$
\therefore-\frac{\eta_{0}-\lambda_{0}}{\alpha_{0}}
$$

where, because of [1i], $v^{2}>0$, if $\alpha_{0} \neq 0$. In [32] and [3t] to [37] all products of the small perturbation quantities $p^{\prime}, T^{\prime}, \rho^{\prime}, v, n$, and $n$ have been neglected in the calculation. In [36], terms have been eliminated due to $[28]_{1}$ and in $[37]$ due to $[30]_{1}$. In the following we shall confune oursetres to the steady-state case. Thus, we obtain from [32] to [38] the following system of linearized fundamental equations,

$$
\begin{aligned}
& \mathbf{v} \cdot \nabla \bar{p}+\bar{p} \nabla \cdot \mathbf{v}=\mathbf{0} \\
& v \cdot \nabla \mathrm{j}=2 \mathrm{nj} \text {, } \\
& (\alpha+\beta+\gamma) \nabla \nabla \cdot \mathbf{n}-\gamma \nabla \times(\nabla \times \mathrm{n})+\varkappa \nabla \times \mathbf{v}-2 \varkappa \mathrm{n}=0 \\
& {\left[\nabla^{2}-v^{2}\right] \mathrm{n}=0} \\
& k \nabla^{2} \mathrm{~T}^{\prime}=v_{3} \frac{\mathrm{d}}{\mathrm{ix}_{3}} \overline{\mathrm{T}}+\mathrm{c} \overline{\mathrm{j}} \nabla \cdot \mathrm{v},
\end{aligned}
$$




$$
\begin{aligned}
& \rho_{0} \delta \mathrm{g} \mathrm{T}^{\prime} \mathrm{e}_{3}-\nabla \mathrm{p}^{\prime}+\lambda_{0} \nabla \mathrm{n}+(\lambda+2 \mu+\varkappa) \nabla \nabla \cdot \mathrm{v}- \\
& -(\mu+\varkappa) \text { curl curl } \mathrm{v}+\varkappa \nabla \times \mathrm{n}=\mathbf{0} .
\end{aligned}
$$

Fquation [45] is obtained by eliminating $\rho^{\prime}$ in [37] by [38]. The equations [32] to [38] form a system of 11 partial differential equations for the determination of the eleven unknown functions $v, n, n, j, \rho^{\prime}$, $\mathrm{T}^{\prime}, \mathrm{p}^{\prime}$.

\section{3. - REDLCTION OF THE PROJBLEN TO AN ORDINARY DIFFERENTIAL EQUATION AND DISCUSSION OF THE SOLUTION}

As we alrealy have started to do with [45], we will show in the following that the system can be decoupled step by step. To eliminate $1^{\prime}$, we take (- curl curl) of $[45]$.

$$
\begin{aligned}
& -\rho_{0} g \delta\left(e_{1} \frac{\lambda^{2}}{\partial x_{1} \partial x_{3}}+e_{2} \frac{\partial^{2}}{\partial x_{2} \partial x_{3}}\right) T^{\prime}+\rho_{0} g \delta e_{3} \nabla_{3}^{\prime \prime} T^{\prime}+ \\
& +(\mu+x) \text { curl curl curl curl } \mathbf{v}-\varkappa \text { curl curl curl } \mathbf{n}=0
\end{aligned}
$$

where

$$
\nabla_{3}^{2}=\frac{\partial^{2}}{\partial x_{1}^{2}}+\frac{\partial^{2}}{\partial x_{2}^{2}}
$$

Let us assume in the following that the divergence of the microrotation disappears.

$$
\nabla \cdot \mathbf{n}=\mathbf{0}
$$

By taking curl, we obtain from [42] and [48]

$-\gamma$ curl curl curl $\mathbf{n}+\varkappa$ curl curl $\mathbf{v}-2 x_{\text {curl }} \mathbf{n}=0$,

$-\varkappa$ curl curl curl curl $\mathbf{n}=-\frac{2 x^{2}}{\gamma} \nabla^{2} \mathbf{n}-\frac{\varkappa^{2}}{\gamma}$ curl curl curl $\mathbf{v}$.

From [10] we obtain

$$
-\nabla \cdot \mathbf{v}=\frac{\mathbf{v} \cdot \nabla \bar{p}}{\bar{p}}=v_{3} \frac{d \ln \bar{p}}{d x_{3}} .
$$

From [44] and [51]

$$
-k \nabla-T^{\prime}=r_{3}\left[c \bar{p} \frac{d \ln \bar{p}}{d x_{3}}-\frac{d \bar{T}}{d x_{:}}\right] .
$$


As a consequence of taking curl, we obtain from [46]

$$
-(\mu+x) \text { curl curl curl curl curl } \mathrm{v}=
$$

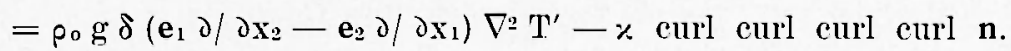

From [50] and [53]

$$
\begin{aligned}
& {\left[-(\mu+x) \text { curl curl }+\frac{x^{2}}{\gamma}\right] \text { curl curl curl } \mathrm{v}=} \\
& =\operatorname{pog}_{\mathrm{g}} \delta\left(\mathrm{e}_{1} \frac{\partial}{\partial \mathrm{x}_{2}}-\mathrm{e}_{2} \frac{\partial}{\partial \mathrm{x}_{1}}\right) \nabla^{2} \mathrm{~T}^{\prime}-\frac{2 x^{2}}{\gamma} \nabla^{2} \mathrm{n} .
\end{aligned}
$$

We apply the operator $\left(-k \nabla^{2}\right)$ to [46] and combine this equation with [52] and [48].

$\mathrm{k}(\mu+\varkappa)$ curl curl curl curl $\nabla^{2} \mathrm{v}=$

$$
\begin{aligned}
& =\rho_{\circ} g \delta\left[\mathbf{e}_{1} \frac{\partial^{2}}{\partial x_{1} \partial x_{3}}+e_{2} \frac{\partial^{2}}{\partial x_{2} \partial x_{3}}-e_{3} \nabla_{3}^{*}\right] \\
& {\left[\frac{d \bar{T}}{d x_{3}}-\bar{n} \frac{d \ln p}{d x_{3}}\right] v_{3}-\mathrm{k} \varkappa \nabla^{2} \nabla^{2} \text { curl } n}
\end{aligned}
$$

The curl of equation [54] yields

$$
\begin{aligned}
& {\left[-(\mu+x) \text { curl curl }+\frac{x^{2}}{\gamma}\right] \text { curl curl curl curl } \mathrm{v}=} \\
& =\rho_{0} g \delta\left(\mathbf{e}_{1} \frac{\partial^{2}}{\partial \mathrm{x}_{1} \partial \mathrm{x}_{3}}+\mathbf{e}_{2} \frac{\partial^{2}}{\partial \mathrm{x}_{2}} \partial \mathrm{x}_{3}-\mathbf{e}_{3} \nabla_{3}^{2}\right) \nabla^{2} \mathrm{~T}^{\prime}-\frac{2^{2}}{\gamma} \nabla^{2} \text { curl } \mathbf{n} .
\end{aligned}
$$

From $[56]$ and [5:2] we obtain

$$
\begin{aligned}
& {\left[-(\mu+x) \text { curl curl }+\frac{x^{2}}{\gamma}\right] \text { curl curl curl curl } \nabla^{2} v=} \\
& =\frac{\rho_{0} g \delta}{k}\left(e_{1} \frac{\partial^{2}}{\partial x_{1} \partial x_{3}}+e_{2} \frac{\partial^{2}}{\partial x_{2} \partial x_{3}}-e_{3} \nabla_{5}^{2}\right) \nabla^{2} . \\
& \cdot\left[\frac{d \bar{T}}{d x_{3}}-\frac{d \ln \bar{p}}{d x_{3}}\right] v_{3}-\frac{\rho \varkappa^{2}}{\gamma} \nabla^{2} \nabla^{2} \text { curl } n .
\end{aligned}
$$

We multiply equation [55] by $2 x / \gamma k$ and subtract therefrom equation $[57]$. 


$$
\begin{aligned}
& {\left[(\mu+\%) \text { curl curl }+\% \frac{2 \mu+\varkappa}{\gamma}\right] \text { curl curl curl curl } \Gamma^{2} \mathbf{v}=[58]} \\
& =\frac{\rho_{0} g \delta}{k}\left(\mathbf{e}_{1} \frac{\partial^{2}}{\partial \mathrm{x}_{1} \partial \mathrm{x}_{3}}+\mathrm{e}_{2} \frac{\partial^{2}}{\partial \mathrm{x}_{2} \partial \mathrm{x}_{3}}--\mathrm{e}_{3} \nabla_{\mathrm{a}}\right) \text {. } \\
& \left.\cdot \mid \nabla=-\frac{2 \%}{\gamma}\right]\left[\operatorname{co} \frac{d \ln \bar{p}}{d \mathrm{x}_{3}}-\frac{\mathrm{dT}}{\mathrm{dx}_{3}} \mid v_{3}\right.
\end{aligned}
$$

Thus, the microrotation $\mathrm{n}$ has been eliminaterl. Using equation [5.1], we now transform equation [58].

$$
\begin{aligned}
& \left.\left.\mid-(\mu+\varkappa) \nabla^{2}+\varkappa \frac{2 \mu+\varkappa}{\gamma}\right] \nabla^{2} \nabla^{2} \mid \nabla^{2} v+\nabla\left(\frac{d \ln \bar{p}_{j}}{d x_{3}} v_{3}\right)\right]= \\
& =\frac{\rho_{0} g}{k}\left(e_{1} \frac{\partial^{2}}{\partial x_{1} \partial x_{3}}+e_{2} \frac{\partial^{2}}{\partial x_{2} \partial x_{3}}-e_{3} \nabla_{3}^{2}\right) \text {. } \\
& \left.\cdot\left[\nabla^{2}-\frac{2 \%}{\gamma}\right] \mid \text { c } \bar{p} \frac{d \ln \bar{p}}{d x_{3}}-\frac{d \bar{T}}{d x_{3}}\right] v_{3} .
\end{aligned}
$$

The 3-component thereof is witten as follows:

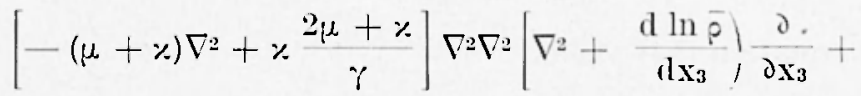

$$
\begin{aligned}
& \left.+\left(\frac{d^{2} \ln \bar{p}}{d x_{3}{ }^{2}}\right)\right] v_{3}=-\frac{\rho_{0} g \delta}{k}\left[\nabla^{2}-\frac{2 \varkappa}{\gamma}\right]\left[c \bar{p} \frac{d \ln \bar{p}}{d x_{3}}-\frac{d \bar{T}}{d x_{3}}\right] \Delta_{b}^{2} v_{3} .
\end{aligned}
$$

Fquation [60] serves for the retermination of $v_{3}$, equation [43] for the rletermination of $\mathrm{n}$. If $\mathrm{j}$ is a function of $\mathrm{x}_{3}$ only, it follows from [+1] that

$$
\frac{d \ln j}{\mathrm{ll}_{3}}=\frac{2 n}{v_{3}} \quad \text { and } \quad j=\exp \left(\frac{2 n}{v_{3}} \mathrm{dx}_{3}\right)
$$

From this equation $\mathrm{j}$ may be calculated following the determination of $v_{3}$ and $n$. However, if $\mathrm{j}$ is a function of $\mathrm{x}_{1}, \mathrm{x}_{2}$, and $\mathrm{x}_{3}$, the function $v_{1}$ has to be calculated from the 1-component of [59] and from $v_{3}$ which is known from the solution of [60]. Accorlingly, the 2 -component of [59] at a known function $r:$ is a differential equation for the rletermination of $v_{2}$. Having, thus, determined $n, v_{1}, v_{2}$, and $v_{3}$ from decoupled differential equations, they are substituted into equation [41] to rletermine $\mathrm{j}$. 
We now want to bring the decisive differential equation [60] closer to the solution. From [60], [29], [30], and [31] we obtain

$$
\begin{aligned}
& {\left[(\mu+x) \nabla^{2}-x \frac{2 \mu+x}{\gamma}\right] \nabla-\nabla^{2}\left[\nabla^{2}+f_{1} \frac{\partial}{\partial x_{3}}+f_{2}\right] v_{3}=} \\
& \left.=-\frac{\rho_{0} g \delta}{k} \mid \nabla^{2}-\frac{2 \varkappa}{\gamma}\right] f_{3} \nabla_{3} v_{3}
\end{aligned}
$$

where

$$
\begin{gathered}
\mathrm{f}_{1}=\mathrm{f}_{1}\left(\mathrm{x}_{3}\right)=-\delta \frac{\rho_{0}}{\rho} \frac{\mathrm{dT}}{\mathrm{dx}:} \\
\mathrm{f}_{2}=\mathrm{f}_{2}\left(\mathrm{x}_{3}\right)=\delta \frac{\rho_{0}}{\rho}\left(\frac{\mathrm{q}}{\mathrm{k}}-\delta \frac{\rho_{0}}{\rho}\left(\frac{\mathrm{dT}}{\mathrm{d} \mathrm{x}_{3}}\right)^{2}\right), \\
\mathrm{f}_{3}=\mathrm{f}_{3}\left(\mathrm{x}_{3}\right)=\left\{1+c \delta \rho_{0}\left|\mathrm{~g}\left(\mathrm{~h}-\mathrm{x}_{3}\right)+\frac{\mathrm{p}_{1}}{\rho}\right|\right\} \frac{\mathrm{lT}}{\mathrm{dx} \mathrm{x}_{3}}
\end{gathered}
$$

and

$$
\begin{gathered}
\overline{p=p_{0}}\left\{1-\delta\left|\frac{q}{2 k}\left(h_{1} x_{3}-x_{3}^{2}\right)-\frac{T_{0}-T_{1}}{i} x_{3}\right|\right\}, \\
\frac{d T}{d x_{3}}=\frac{q}{k}\left(\frac{h}{2}-x_{3}\right)-\frac{T_{0}-T_{1}}{h} .
\end{gathered}
$$

For the diflerential equation [62] we assume a separable solution.

$$
v_{3}=w\left(x_{3}\right) f\left(x_{1}, x_{2}\right)
$$

with

$$
\nabla_{3} f\left(x_{1}, x_{2}\right)+\frac{a^{2}}{h^{2}}-f\left(x_{1}, x_{2}\right)=0
$$

where a is the aspect latio of the cells. From [68] and [69] we have

$$
\nabla_{3} r_{3}=-\frac{a^{2}}{h^{2}} r_{3}
$$

We define

$$
\zeta=\frac{x_{3}}{h} \quad \text { and } \quad \text { D }=\frac{\partial}{\partial \zeta} .
$$

From [70] and [71]

$$
\nabla \cdot r_{3}=\left(\nabla_{3}^{*}+\frac{\partial^{2}}{\partial x_{3}^{2}}\right) r_{3}=\frac{1}{\mathrm{~h}^{2}}\left(T^{2}-a^{2}\right) r_{i} .
$$

From $[62]$ 


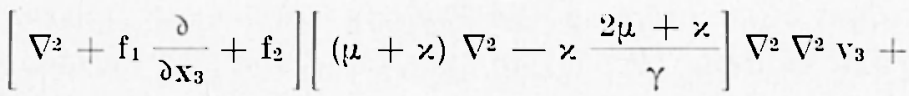

$$
\begin{aligned}
& +\frac{\partial \mathrm{v}_{3}}{\partial \mathrm{x}_{3}}\left[(\mu+\varkappa) \nabla^{2}-\varkappa \frac{2 \mu+\varkappa}{\gamma}\right] \nabla^{2} \nabla^{2} \mathrm{f}_{1}+ \\
& +v_{3}\left[(\mu+x) \nabla^{2}-x^{2 \mu}+\gamma^{2} \nabla^{2} \mathrm{f}_{2}=\right. \\
& =-\frac{\rho_{0}}{\mathrm{k} \delta} \mathrm{f}_{3}\left[\nabla^{2}-\frac{2 \chi}{\gamma}\right] \nabla_{0}^{-} \mathrm{v}_{3}-\frac{\rho_{0} g \delta}{\mathrm{k}} \Gamma_{3}^{2} \mathrm{v}_{3}\left[\nabla^{2}-\frac{2 \varkappa}{\gamma}\right] \mathrm{f}_{3} .
\end{aligned}
$$

By introrlueing the statement [68] into equation [73] and multiplying the resulting relationship by $h^{8} /(\mu+x)$, we obtain

$$
\begin{aligned}
& {\left[\left(D^{2}-a^{2}\right)+f_{4} D+f_{5}\right]\left[\left(D^{2}-a^{2}\right)-k_{1}\right]\left(D^{2}-a^{2}\right)^{2} w+} \\
& +f_{6} D w+f_{7} W^{2}=R_{1}\left\{f_{8}\left[\left(D^{2}-a^{2}\right)-k_{2}\right]+f_{9}\right\} a^{2} w^{2}
\end{aligned}
$$

where

$$
\begin{aligned}
& \mathrm{f}_{4}=\mathrm{f}_{4}\left(\mathrm{x}_{3}\right)=h \mathrm{f}_{1}\left(\mathrm{x}_{3}\right), \\
& \mathrm{f}_{5}=\mathrm{f}_{5}\left(\mathrm{x}_{3}\right)=\mathrm{h}^{2} \mathrm{f}_{2}\left(\mathrm{x}_{3}\right), \\
& \mathrm{f}_{6}=\mathrm{f}_{6}\left(\mathrm{x}_{3}\right)=\mathrm{h}\left[\mathrm{I}^{2}-\mathrm{k}_{1}\right] \mathrm{D}^{-4} \mathrm{f}_{1}\left(\mathrm{x}_{3}\right), \\
& \mathrm{f}_{7}=\mathrm{f}_{7}\left(\mathrm{x}_{3}\right)=\mathrm{h}^{2}\left[\mathrm{D}^{2}-\mathrm{k}_{1}\right] \mathrm{I}^{-4} \mathrm{f}_{2}\left(\mathrm{x}_{3}\right), \\
& \mathrm{f}_{0}=\mathrm{f}_{8}\left(\mathrm{x}_{3}\right)=\frac{\mathrm{h} \mathrm{f}_{3}\left(\mathrm{x}_{3}\right)}{\mathrm{T}_{6}-\mathrm{T}_{1}}, \\
& \mathrm{f}_{9}=\mathrm{f}_{9}\left(\mathrm{x}_{3}\right)=\frac{h^{\prime}}{\mathrm{I}_{0}-\mathrm{T}_{1}}\left[\mathrm{D}^{2}-\mathrm{k}_{2}\right] \mathrm{f}_{3}\left(\mathrm{x}_{3}\right)
\end{aligned}
$$

and

$$
\begin{aligned}
& R_{1}=\frac{\left(x \delta h^{3}\left(\mathrm{~T}_{0}-\mathrm{T}_{1}\right) p_{0}\right.}{k(\mu+\varkappa)}, \\
& \mathrm{k}_{1}=\frac{\varkappa}{\gamma} \frac{2 \mu+\varkappa}{\mu+\varkappa} \mathrm{h}^{2} ; \quad \quad \therefore=\frac{2 \varkappa}{\gamma} \mathrm{h}^{2} .
\end{aligned}
$$

$\mathrm{R}_{1}, \mathrm{k}_{1}$, and $\mathrm{k}_{2}$ are dimensionless constants. If $\times$ disappeared, $\mathrm{R}_{1}$ would be irlentical with the conventional Rayleigh number. All quantities occurring in equation [74] are dimensionless. With the derivation of equation [7.t] it was possible to reduce the problem to an ordinary differential equation of the 8 th order for $w$ as a function of $\zeta$. Equation [74] ofter's a farourable starting point for a numerical solution of the problem. Eq. [7+] cannot be solverl analytically, because dependencies on $\zeta$ are still existing in $f_{4}, \ldots, f_{9}$. In $\left({ }^{16}\right)$ it is shown how in the 
special case of an incompressible micropolar fluid without microstretch and without internal heat soures the general solution of [7.t] can be analytically given and how its constants can be determined according to the boundary conditions. If only the intermal heat sources disappeared, i. e., if $q=0$, a micropolar stretch fluid would be described by formula $[\tau+t]$ with the following simplified expressions for $f_{4}, \ldots, f_{9}$.

$$
\begin{aligned}
& \mathrm{f}_{4}=\left[\zeta+\delta^{-1}\left(\mathrm{~T}_{0}-\mathrm{T}_{1}\right)^{-1}\right]^{-1}, \\
& \mathrm{f}_{5}=-\left[\zeta+\delta^{-1}\left(\mathrm{~T}_{0}-\mathrm{T}_{1}\right)^{-1}\right]^{-2}, \\
& \mathrm{f}_{6}=\left[\mathrm{D}^{2}-\mathrm{k}_{1}\right] \mathrm{I}^{4}\left[\zeta+\delta^{-1}\left(\mathrm{~T}_{0}-\mathrm{T}_{1}\right)^{-1}\right]^{-1}, \\
& \mathrm{f}_{7}=-\left[\mathrm{D}^{2}-\mathrm{k}_{1}\right] \mathrm{D}^{4}\left[\zeta+\delta^{-1}\left(\mathrm{~T}_{0}-\mathrm{T}_{1}\right)^{-1}\right]^{-2}, \\
& \left.\mathrm{f}_{8}=-\left\{1+c \delta \rho_{0} \mid \operatorname{gh}(1-\zeta)+\frac{\mathrm{p}_{1}}{\rho_{0}\left(1+\delta\left(\mathrm{T}_{0}-\mathrm{T}_{1}\right) \zeta\right)}\right]\right\}, \\
& \left.\mathrm{f}_{9}=-\left[\mathrm{D}^{2-}-\mathrm{k}_{2}\right]\left\{1+c \delta \rho_{0} \mid \operatorname{gh}(1-\zeta)+\frac{\mathrm{p}_{1}}{\rho_{0}\left(1+\delta\left(\mathrm{T}_{0}-\mathrm{T}_{1}\right) \zeta\right)}\right]\right\} .
\end{aligned}
$$

Equations [83] to [88] show that, even if we neglect internal heat sources, the solution $w(\zeta)$ cannot be analytically given for a micropolar stretch fluid, since the $f_{4}, \ldots, f_{0}$ explicitely contain the quantity $\zeta$ also in that case. Therefore, we may just as well solve the full problem $[74]$ to $[82]$ in the numerical calculations, with $q \neq 0$. The main problem, namely to reduce the system ([8] to [14]) from eleven partial differential equations with eleven unknown functions and four independent variables to an ordinary diflerential equation with one sought function and one independent variable, however, has been solverl. Finally, we will derive the boundary conditions for w.

\section{4. - BOUNDARY COXDITIONS}

It is obvious that for convection in the asthenosphere the case of fixed, rigid boundaries is most important, so that we will exclusively deal with this case here. The formulas [89] to [95] as well as [97] and [98] hold only at the boundaries $\zeta=0$ and $\zeta=1$ of the layer.

$$
\mathrm{v}=0 ; \quad \mathrm{n}=0 ; \quad \mathrm{n}=0
$$

Because the temperature at the boundary surfaces is to be kept constant, we have

$$
\mathrm{T}^{\prime}=0
$$


From $[89]_{1}$

$$
\mathrm{w}=\mathbf{0}
$$

From [90] it follows that $\bar{T}=$ const; from this and from [31] it follows that $\rho=$ const; from this, from $[40]$, and $[89]_{1}$ we obtain

$$
\text { Dw }=0 \text {. }
$$

From $[89]_{2}$

$$
\text { curl } \mathbf{n}=-\frac{\partial n_{0}}{\partial x_{3}} \mathbf{e}_{1}+\frac{\partial n_{1}}{\partial x_{3}} e_{3}
$$

From [46], [48], [90], and [93]

$$
0=\mathrm{e}_{3} \cdot(\text { curl curl curl curl } \mathrm{v})=\nabla=\nabla^{2} \mathrm{v}_{3}+\nabla=\frac{\partial}{\partial \mathrm{x}_{3}}\left(\frac{\mathrm{l} \ln \overrightarrow{\mathrm{P}}_{\mathrm{v}_{3}}}{\mathrm{d \textrm {x } _ { 3 }}}\right)
$$

Since $\frac{\partial v_{3}}{\partial x_{1}}=\frac{\partial v_{3}}{\partial x_{2}}=0$ and $-\frac{\partial \rho}{\partial x_{1}}=\frac{\partial \bar{\rho}}{\partial x_{2}}=0$ it follows that

$$
\frac{\partial^{4}}{\partial x_{3}^{4}} v_{3}+\frac{\partial x^{3}}{\partial x_{3}^{3}}\left(\frac{d \ln \bar{p}}{d x_{3}} v_{3}\right)=0
$$

From [48] and [49] we obtain

$$
\text { curl curl } \mathbf{v}=\left(2-\frac{\gamma}{x} \nabla^{2}\right) \text { curl } \mathrm{n} \text {. }
$$

From [ั51], [93], and [96]

$$
\begin{aligned}
& \mathrm{e}_{3} \cdot \operatorname{curl} \cdot \operatorname{mrl} \mathrm{v}=\mathrm{e}_{\mathbf{3}} \cdot\left(\nabla \nabla \cdot \mathrm{v}-\nabla^{2} \mathrm{v}\right)= \\
& \left.=-\mathbf{e}_{3} \cdot \operatorname{IV}\left(\mathbf{v}_{3} \frac{\mathrm{d} \ln \bar{p}}{d x_{3}}\right)+\nabla^{2} \mathbf{v}\right]=0, \\
& \frac{\partial^{2}}{\partial x_{3}^{2}} v_{3}+\frac{\partial}{\partial x_{3}}\left(\frac{d \ln p}{d x_{3}} v_{3}\right)=0 .
\end{aligned}
$$

Let us now introduce some derivatives taken at the upper and lower boundary planes

$$
\begin{aligned}
& \frac{\mathrm{d} \ln \rho}{\mathrm{dx} \mathrm{x}_{3}}\left|\zeta=0=h^{-1} \Lambda_{0} ; \quad \frac{\mathrm{l} \ln \bar{p}}{\mathrm{dx_{3 }}}\right| \zeta=1=h^{-1} A_{1}, \\
& \left.\frac{\mathrm{d}^{2} \ln \rho}{\mathrm{d} x_{3}^{2}}\right|_{\zeta=0}=\mathrm{h}^{-2} \mathrm{~B}_{0} ; \quad \frac{\mathrm{d}^{2} \ln p}{\mathrm{~d} x_{i}^{2}} \mid \zeta=1=\mathrm{i}^{-2} \overline{\mathrm{D}}_{1}, \quad[100] \\
& \frac{\mathrm{d}^{4} \ln \rho}{d x_{3}^{4}}\left|\zeta=0=h^{-1} \mathrm{C}_{0}, \quad \frac{\mathrm{d}^{4} \ln \overline{0}}{d x_{3}^{1}}\right| \zeta=1=h^{-4} \mathrm{O}_{1}
\end{aligned}
$$


The quantities $A_{0}, A_{1}, B_{0}, B_{1}, C_{0}$, and $C_{1}$ defined by [99] to [101] are dimensionless constants, e. g.,

and

$$
\Lambda_{0}=\delta\left\{\left(T_{0}-T_{1}\right)-\frac{q h^{2}}{2 k}\right\}
$$

$$
\Lambda_{1}-\frac{\left(\mathrm{T}_{0}-\mathrm{T}_{1}\right)+\left(\mathrm{q}_{1} 2 /(2 \mathrm{k})\right.}{\left(\mathrm{T}_{0}-\mathrm{T}_{1}\right)+\delta^{-1}}
$$

By means of these six constants equations [98] and [95] can be transformed as follows.

$$
\begin{aligned}
& \mathrm{D}^{2} w+A_{\zeta} \mathrm{D} w+\mathrm{B}_{\zeta} w=0 \text { for } \zeta=0 \text { and } \zeta=1, \\
& \mathrm{D}^{1} w+A_{\zeta} \mathrm{D}^{3} w+\mathrm{C}_{\zeta} w=0 \text { for } \zeta=0 \text { and } \zeta=1
\end{aligned}
$$

Thus, the boundaly conclitions the solution $w$ of [7t] must satisfy at the boundaries $\check{\zeta}=0$ and $\zeta=1$ can be summanized as follows:

$$
\mathrm{w}=\mathrm{Dw}=\left(\mathrm{D}^{2}+\mathrm{A}_{\zeta} \mathrm{D}+\mathrm{B}_{\zeta}\right) \mathrm{w}=\left(\mathrm{D}^{4}+\mathrm{A}_{\zeta} \mathrm{D}^{3}+\mathrm{C}_{\zeta}\right) \mathrm{w}=0 .
$$

In the special case of an incompressible micropolar fluid without

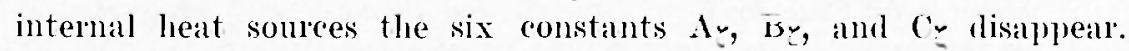

\section{Conclusions}

Whatever the principal driving mechanism for the motion of the lithospheric plates may be, it is obvious that lattice and radiative themal diffusivities of mantle rock are not sufficient to explain the heat flux observed at the surface of the Earth. Therefore, there must be convection in the mantle and particularly in the asthenosphere. If it is assumed (1) that the low-velocity layer is partly molten and that there is a geometrical comnectivity between the solid and liquid phases in the form (see Fig. 1) suggested by Stocker and Ashby (12), a layel of a micropolar stretch fuid with internal heat sources may be introduced as a model for the asthenospliere. Hence, the Binard problem of this model has to be solved, the case of fixed, rigid boundaries being of interest. The dymamic fundamental equations form a system of eleven partial differential equations. The essential object of the present paper is to show how the equations can be decoupled and the problem be reduced to an ordinary differential equation, which is a suitable starting point for numerical calculations. In all the calculations the Boussinesq approximation has not been used and stretch and microstretch have been considered. In the special case of a micropolat fluid without stretch the solution can even be given analytically. 


\section{REFERENCLS}

(1) Axpersox D. I. and Sammis C., 1970. - Partial Melting of the Upper Manlle. "Phys. Earth and Planet. Interiors", 3, pp. 41-50.

(2) Boscin E., 1973. - Lamb and Love Tave Propagalion in an Infinile Hicropolar Elastic Plale. "Annali di Geolisica", XXVI, pp. 341-355.

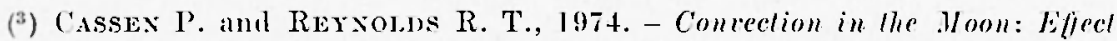
of Tariable Viscosily. "J. geophys. Res.", 79. pp. 2937-2944.

(') ChandRasekinar s., 1961. - Mydrodynamic and Mydromagnetic stability. Oxford.

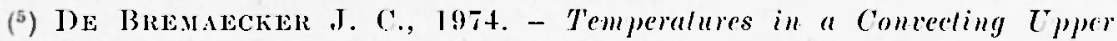
Ianlle. "Tectonophysies", 21, pl. 1-13.

${ }^{(6)}$ Ernocax M. E., 1972. - Dynamies of Polar Fluids. "Acta Mechanica", 15.

(7) ERrvese A. C., 1969. - Micropolar Fluids wilh sireteh. "Int. Journal Engng. Sci.", 7, pp. 115.127.

$\left({ }^{8}\right)$ KiRnY s. H. and RALEIGH C. B., 1973. - Mechanisms of Migh-Temperalure, Solid-slale Flow in Minerals and Voramics and Their Bearing on the (reep Beharior of the Manlle. "Teetonophysies", 19, plp. I (55-194.

$\left({ }^{9}\right)$ UCKExze I). and Werss X., 1975. - Sperulations on the Thermal and Tectonic II istory of the Earth. "G(ophys. J. R. astr. Soc.", 42, p1). 131. 174.

$\left({ }^{10}\right)$ Post R. J., Jr. and Grigas D). T., 1973. - The Earthis Manlle: Eridence of Non- Vertonian Flow. "Science", 181, 4166, pl. 1242-1244.

(11) Riciter F. M. and Parsoxs B., 1975. - On the Interction of Two Scales of Convection in the .lantle. "J. greophys. Res.", 80, plp. 2529-25+1.

${ }^{\left({ }^{12}\right)}$ Strocker R. I. and Asmbx M. F., 1973. - On the Rheology of the Tpper Monlle. "Rev. Geophyss. and space Phys.", 11, ple. 391-426.

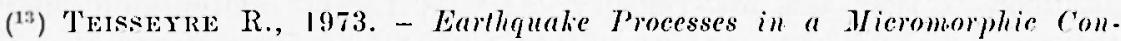
timun. "Pure and Appl. Geophysics", 102 I, pl. 15-28.

${ }^{(14)}$ Turcote .D. L., Torrance K. F. and HeU A. T., I973. . Conrection in the Earll's Mantle. "Methods in Computational Physies", 13, 1). $43 \mathrm{I}-454$.

$\left({ }^{15}\right)$ Watzer Li., 1973. - A Quantilatire Fimemalie Theory of Concelion currents in the Earth's Mantle. "Pure and Appl. Geophysics", 105, IV, p). 669-695.

${ }^{(16)}$ Watzer V., 1976. - Comection of a Cosscral Fluid. "Gicrlands Beitr. Geoplyysik", 85, 2, pम. 137-150.

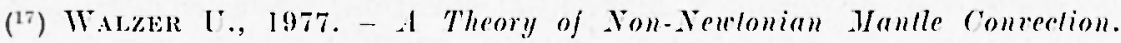
"Gerlands Beitr. (reoplıysik", 86, I, pl). 5l-61.

$\left.{ }^{18}\right)$ Wentтux J., 1970. - The creep Strenglh of the Earth's Manile. "Rov. Geophys. Space Phys.", 8, pl' 145-168. 